\title{
Postpartum fertility behaviours and contraceptive use among women in rural Ghana
}

\author{
Sebastian Kofi Eliason ${ }^{1 *}$, Ansumana Sandy Bockarie ${ }^{1}$ and Cecilia Eliason ${ }^{2}$
}

\begin{abstract}
Background: Although most women would want to wait for more than two years before having another baby, their fertility behaviours during the first year following birth may decrease or increase the length of the birth interval. The objectives of this study were to: assess how protected postpartum women in the Mfantseman municipal were against pregnancy, based on their patterns of amenorrhoea and sexual abstinence; determine the timing of postpartum contraception in relation to amenorrhoea and sexual abstinence; and determine the predictors of postpartum contraceptive use.
\end{abstract}

Methods: This was a prospective study carried out in the Mfantseman Municipality of the Central region of Ghana. Out of 1914 women attending antenatal clinic in the municipal within the study period, 1350 agreed to be part of the study to ascertain their postpartum fertility and contraceptive behaviours a year following delivery. These women were traced to their communities using telephone and house numbers provided and only 1003 of the women were finally traced and interviewed. The women were asked about their breastfeeding behaviour, postpartum sexual abstinence, duration of amenorrhoea and postpartum contraceptive use.

Results: The mean age of the respondents was $29.9 \pm 6.5$ years; adolescents constituted the least proportion (3.3\%) of the women. More than half (54.1\%) of the women had Middle, Junior secondary school or Junior high school education. Most (43.3\%) of the women were married by means of traditional rites and more than half (51.4\%) of them were petty traders. The mean durations of breastfeeding, amenorrhoea and sexual abstinence were $6.6 \pm 2$. 8 months, $7.8 \pm 3.8$ months and $4.4 \pm 3.1$ months respectively, whilst mean time of first contraceptive uptake was 3 . $5 \pm 2.7$ months postpartum. The time to first use of modern contraceptive method during the postpartum period indicates that about $50 \%$ of the women had started use of modern contraceptive methods by 2.7 months postpartum, and occured 0.6 and 3.6 months before sexual relations and resumption of menses respectively. Occupation (likelihood ratio $p=0.013$ ), area of residence (likelihood ratio $p=0.004$ ), mode of delivery (likelihood ratio $p<0.001)$, breastfeeding $(p=0.024)$, period since delivery $(p<0.001)$, preferred number of children $(p<0.001)$ and parity $(p<0.001)$ were found to be predictors of postpartum contraceptive use.

Conclusion: Postpartum women in the Mfantseman municipal who did not use contraceptives or delayed in the use of contraceptives after birth were least likely to be protected against pregnancy in the post partum period, whilst those who adopted postpartum family planning were likely to be better protected because they were likely to adopt it within the first three months after birth and before the onset of sexual relations and first menses. The predictors of postpartum contraceptive use were breastfeeding pattern, occupation, parity, preferred number of children, period since delivery, place of residence and mode of delivery.

Keywords: Postpartum, Contraceptive use, Breastfeeding, Amenorrhoea, Sexual abstinence

\footnotetext{
* Correspondence: s.eliason@uccsms.edu.gh

'Department of Community Medicine, School of Medical Sciences, University

of Cape Coast, Cape Coast, Ghana

Full list of author information is available at the end of the article
}

(c) The Author(s). 2018 Open Access This article is distributed under the terms of the Creative Commons Attribution 4.0 International License (http://creativecommons.org/licenses/by/4.0/), which permits unrestricted use, distribution, and

reproduction in any medium, provided you give appropriate credit to the original author(s) and the source, provide a link to the Creative Commons license, and indicate if changes were made. The Creative Commons Public Domain Dedication waiver (http://creativecommons.org/publicdomain/zero/1.0/) applies to the data made available in this article, unless otherwise stated. 


\section{Plain English text}

Although most women would want to wait for more than two years before having another baby, their fertility behaviours during the first year after birth may decrease or increase the length of the birth interval. The objectives of this study were to: assess how protected postpartum women were against pregnancy, based on their patterns of amenorrhoea and sexual abstinence; determine the timing of postpartum contraception in relation to amenorrhoea and sexual abstinence; and determine the predictors of postpartum contraceptive use.

This was a prospective study carried out in the Mfantseman Municipality of the Central region of Ghana. Out of 1914 women attending antenatal clinics in the municipal within the study period, 1350 agreed to be part of the study to ascertain their postpartum fertility and contraceptive behaviours a year following delivery. These women were traced to their communities using telephone and house numbers provided and only 1003 of the women were finally traced and interviewed. The women were asked about their breastfeeding behaviour, postpartum sexual abstinence, duration of amenorrhoea and postpartum contraceptive use.

The mean age of the respondents was $29.9 \pm 6.5$ years; adolescents constituted the least proportion (3.3\%) of the women. More than half (54.1\%) of the women had Middle, Junior secondary school or Junior high school education. Most (43.3\%) of the women were married by means of traditional rites and more than half $(51.4 \%)$ of them were petty traders. The mean durations of breastfeeding, amenorrhoea and sexual abstinence were $6.6 \pm 2.8$ months, $7.8 \pm$ 3.8 months and $4.4 \pm 3.1$ months respectively, whilst the mean time of first contraceptive uptake was $3.5 \pm 2.7$ months postpartum. The time to first use of modern contraceptive method during the postpartum period indicates that about $50 \%$ of the women had started use of modern contraceptive methods by 2.7 months postpartum, and occured at 0.6 and 3.6 months before sexual relations and resumption of menses respectively. Occupation (likelihood ratio $p=0.013$ ), area of residence (likelihood ratio $p=0.004$ ), mode of delivery (likelihood ratio $p<0.001)$, breastfeeding $(p=0.024)$, period since delivery $(p<0.001)$, preferred number of children $(p<0.001)$ and parity $(p<0.001)$ were found to be predictors of postpartum contraceptive use.

Postpartum women in the Mfantseman municipal who did not use contraceptives or delayed in the use of contraceptives after birth were least likely to be protected against pregnancy in the postpartum period, whilst those who adopted postpartum family planning were likely to be better protected because they were likely to adopt it within the first three months after birth and before the onset of sexual relations and first menses. The predictors of postpartum contraceptive use were breastfeeding pattern, occupation, parity, preferred number of children, period since delivery, place of residence and mode of delivery.

\section{Background}

The 2006 World Health Report proposed a 2-3 year birth interval and a six month conception interval following miscarriage or abortion, because they ensured good maternal and child health outcomes [1]. Evidence exists that if couples could space their pregnancies by at least two years, up to $35 \%$ of maternal deaths and up to $13 \%$ of child mortalities could be averted [2-4], whilst $25 \%$ of under - five mortalities could be averted if birth intervals were at least three years [3].

Although most women would want to wait for more than two years before having another baby, their fertility behaviours during the first year following birth may decrease or increase the length of the birth interval [5]. These behaviours include breastfeeding and its influence on return of menses (postpartum amenorrhoea), return to sexual activity (postpartum sexual abstinence) and use of maternal health services. Some of these behaviours biologically reduce fertility while some affect decisions to use family planning during the postpartum period [5].

Women are not at risk of pregnancy following a birth if they are amenorrhoeic as a result of intensive exclusive breastfeeding or abstaining from sex [6]. The period of insusceptibility, which is influenced by sexual abstinence and exclusive breastfeeding, lengthens the time until the next conception. Use of contraception within this period offers extra protection against the risk of pregnancy [7]. The length and intensity of breastfeeding and the length of amenorrhea and sexual abstinence vary among women and within societies. In this respect, postpartum behaviours need to be understood in relation to the contraception behaviours of women [7] if unintended pregnancies are to be avoided. The objectives of this study were to: assess how protected postpartum women in the Mfantseman municipal were against pregnancy, based on their patterns of amenorrhoea and sexual abstinence; determine the timing of postpartum contraception in relation to amenorrhoea and sexual abstinence; and determine the predictors of postpartum contraceptive use.

\section{Methods}

\section{Study area}

The study was carried out in the Mfantseman Municipal area of the Central Region of Ghana. This is a coastal and predominantly rural district in the southern part of Ghana. The main ethnic group is Fante. The main occupation of the people in the district are farming, fishing and trading.

The area was selected because of the high levels of teen pregnancies (13.6\% of all pregnancies) high abortion rates amongst the teens and very low family planning uptake which had been consistently below 10\% over a three year period from 2007 to 2009 according to the 2010 annual report of the Municipal Health Directorate [8]. 


\section{Study design and data source}

This was a prospective study of postpartum women who had been encountered earlier at antenatal clinic in four selected health facilities in the Mfantseman Municipal area (Saltpond hospital, Mankessim health centre, Anomabo and Biriwa health centres) where their intention to use postpartum family planning was ascertained. These women agreed to be followed up to their communities within a year following delivery to ascertain their postpartum reproductive and contraceptive behaviours. Data on duration of breastfeeding, amenorrhoea and sexual abstinence, and time of first contraceptive use, continuation or discontinuation, were obtained within one calendar year after last birth using a reproductive event sheet adapted from DHS contraceptive calendar. The data sheets captured month-by-month data on contraceptive use or non-use, continuation or discontinuation of contraception, breastfeeding patterns, sexual behaviour and menstrual resumption to cover period since last birth. The data sheets were reviewed one year postpartum at the time of interview; however, periodic contacts with the respondents were done through telephone calls, home visits and personal contacts to ensure they were capturing data consistently and to clarify any issues that may have arisen. Reasons for use, non-use and discontinuation if any, were obtained from participants at the time of the interview. Information on socio-demographic and socio-economic characteristics was also obtained.

\section{Sample size estimation and sampling}

Based on an estimated target population of 4218 (Average total number of women visiting ANC at all selected health facilities per quarter, per year from 2008 to 2010) and the assumption that $50 \%$ of pregnant women intended to adopt postpartum family planning, within a margin of error of 3\%, a minimum sample size ST, was estimated as follows: For a finite population, the sample size ST, was estimated by the formula: $\mathrm{ST}=\mathrm{A} /[1+(\mathrm{A}-1) / \mathrm{T}]$ [9], where $\mathrm{A}$ is given by $\left[\mathrm{Z}^{2 *} \mathrm{P} *(1-\mathrm{P})\right] / \mathrm{C}^{2} ; \mathrm{T}=$ estimated target population; $Z=Z$ value (1.96 for $95 \%$ confidence); $P=$ Proportion of pregnant women who intended to adopt postpartum family planning; and $\mathrm{C}=$ margin of error. This implies, $\mathrm{A}=\left[1.96^{2}(0.5)(0.5)\right] / 0.03^{2}=1067$ and $\mathrm{ST}=1067$ / $[1+(1067-1) / 4218]=852$; (approximated to 900). To take care of defaults and late ANC registrations (each constituting $50 \%$ of computed sample size) respectively [10], the minimum sample size $(\mathrm{ST}=900)$ was doubled to 1800 with an additional 10\% mark-up for women who would decline to be interviewed. The estimated total sample size was 1980 . Within the survey period (2nd January to 30th April 2012), each of the selected health facilities was visited during the days designated for antenatal clinic. At the selected health facilities, all antenatal registrants (pregnant women), irrespective of the period of gestation, who lived in the Mfantseman Municipal area and who were aged 15 to 49 years, were targeted to be part of the study. During the prenatal phase of the study, 1914 antenatal registrants were encountered. Sampling of these was by total enumeration technique. Each of the antenatal registrants was asked if they would wish to be followed up a year after they had delivered to find out about contraceptive use and other reproductive health behaviours. Only 71\% (1359) of them agreed to be followed up after delivery. The other $29 \%$ declined follow up for religious, socio-cultural and personal reasons considering the sensitive nature of family planning within such communities.

Several strategies to further reduce non-response and attrition and improve retention rates were employed in this study. These included the following: first, giving detailed explanations about the study objectives and its possible impacts on the individual, family and society and allaying any anxieties and fears about participating in the study, whilst ensuring that emotional support was on hand to deal with extreme cases; second, obtaining detailed personal information including names, telephone numbers, house addresses (where available) and detailed descriptions of directions to houses of respondents; third, providing adequate motivation for participation by ensuring that the research assistants were friendly, showed respect and courtesy to the respondents and provided adequate privacy at the environment of the interview; fourth, improving rapport between research team and respondents by making periodic contacts with the respondents who agreed to be followed up through telephone calls, home visits and personal contacts; fifth, providing learning opportunities to the research assistants by the comprehensive training given. This motivated the research assistants to engage the respondents in ways that improved rapport and encouraged participation; sixth, providing research assistants in Phase 2 additional incentives for transportation to help them access all the respondents assigned to them, especially to the remotest parts of the municipality and seventh, regular sensitization about the study carried out by the Municipal Health Directorate through their health centres, outreach points and home visits.

These strategies notwithstanding, only 1003 (74\%) of the 1359 who agreed to be followed up were encountered. Twenty-six percent (26\%) could not be traced mainly because of poor address systems in the communities and non-functional telephone numbers. Follow up interviews were carried out from 2nd January to 30th May 2014. These were done via face-to-face and telephone interviews using home addresses and telephone numbers provided.

\section{Data management and analysis}

The data obtained were double-entered using EPI-DATA, verified and cleaned. The cleaned data were exported into STATA (version 11) for analysis. Descriptive, chi square 
and logistic regression statistics were carried out to describe the socio-demographic and socio-economic characteristics of respondents, determine associations between contraceptive use and breastfeeding, amenorrhoea and sexual abstinence and determine the predictors of postpartum contraceptive use, respectively. Survival analysis techniques were used to assess the time to resumption of menstrual flow, resumption of sexual activities and time to first contraceptive use.

\section{Results}

\section{Socio-demographic characteristics of respondents}

Table 1 presents the distribution of socio-demographic characteristics of respondents in this study. The mean age of the respondents was $29.9 \pm 6.5$ years. Majority (73.9\%) of the women were in their prime age (20-34 years) whilst adolescents constituted the least proportion $(3.3 \%)$ of the women. More than half (54.1\%) of the women had attained Middle, Junior secondary school (JSS) or Junior high school(JSS) education and a little above 8\% (8.3\%) had no formal education. The ethnic group with the highest proportion was Fante (88.7\%). Christians were the majority $(90.3 \%)$ religious group among the women, followed by the Muslims (7.6\%). Most (43.3\%) of the women had married by means of traditional rites and more than half $(51.4 \%)$ of them were petty traders.

\section{Breastfeeding, amenorrhoea, sexual abstinence and contraceptive use postpartum}

The mean durations of breastfeeding, amenorrhoea and sexual abstinence were $6.6 \pm 2.8$ months, $7.8 \pm 3.8$ months and $4.4 \pm 3.1$ months respectively. The mean time of first contraceptive uptake following the last birth among women who had used contraceptives was $3.5 \pm 2.7$ months. Table 2 shows the length of breastfeeding, amenorrhoea and sexual abstinence and time of first contraceptive uptake since the last birth. Among those who breastfed, majority (71.6\%) had breastfed for six months whilst majority (62.5\%) had remained amenorrheic for seven months up to a year.

The period of sexual abstinence among the postpartum women was relatively shorter. Majority (66.2\%) had abstained for periods of one to four months following birth. Out of the 1003 postpartum women interviewed, $505(50.3 \%)$ of them reported using contraceptives following birth, however only 422 provided correct information regarding time of contraceptive use following birth. None of these women reported any discontinuation once they started using contraceptives of their choices. The 83 women dropped had incorrect or inconsistent data or had missing information on record sheets. Nearly $66 \%$ had used contraceptives between the first and third month after birth. The most common methods used were male condoms (33.7\%), injectables (30.3\%) and pills (20.6\%) respectively (Fig. 1).
Table 1 Socio-demographic Characteristics of Respondents

\begin{tabular}{|c|c|c|}
\hline Variable & $\begin{array}{l}\text { Number } \\
N=1003\end{array}$ & Percentage (\%) \\
\hline \multicolumn{3}{|l|}{ Age } \\
\hline $15-19$ & 33 & 3.3 \\
\hline $20-34$ & 741 & 73.9 \\
\hline $35-39$ & 132 & 13.2 \\
\hline $40+$ & 97 & 9.7 \\
\hline \multicolumn{3}{|l|}{ Educational level } \\
\hline None & 83 & 8.3 \\
\hline Primary & 214 & 21.3 \\
\hline $\begin{array}{l}\text { Middle/Junior secondary School/ } \\
\text { Junior high school }\end{array}$ & 543 & 54.1 \\
\hline $\begin{array}{l}\text { Secondary/Senior secondary school/ } \\
\text { Senior high School Nocational }\end{array}$ & 119 & 11.9 \\
\hline Tertiary & 44 & 4.4 \\
\hline \multicolumn{3}{|l|}{ Ethnicity } \\
\hline Fante & 890 & 88.7 \\
\hline Efutu & 18 & 1.8 \\
\hline Other Akan & 46 & 4.6 \\
\hline Ewe & 21 & 2.1 \\
\hline Hausa & 22 & 2.2 \\
\hline Other & 6 & 0.6 \\
\hline \multicolumn{3}{|l|}{ Religion } \\
\hline Christian & 906 & 90.3 \\
\hline Muslim & 76 & 7.6 \\
\hline Other & 21 & 2.1 \\
\hline \multicolumn{3}{|l|}{ Occupation } \\
\hline Fishmonger & 69 & 6.9 \\
\hline Farmer & 33 & 3.3 \\
\hline Petty Trader & 515 & 51.4 \\
\hline Civil/Public Servant & 111 & 11.1 \\
\hline Student & 32 & 3.2 \\
\hline Other & 243 & 24.2 \\
\hline \multicolumn{3}{|l|}{ Area of residence } \\
\hline Saltpond & 316 & 31.5 \\
\hline Biriwa & 135 & 13.5 \\
\hline Anomabo & 179 & 17.9 \\
\hline Mankessim & 259 & 25.8 \\
\hline Other & 114 & 11.4 \\
\hline \multicolumn{3}{|l|}{ Marital Status } \\
\hline $\begin{array}{l}\text { Married through church/mosque/ } \\
\text { court wedding }\end{array}$ & 213 & 21.2 \\
\hline Married only by traditional rite & 434 & 43.3 \\
\hline Engaged, yet to be married & 240 & 23.9 \\
\hline Co-habitation (living together) & 73 & 7.3 \\
\hline Divorced/Separated/Widow/Single & 43 & 4.3 \\
\hline
\end{tabular}

Source: Field data (2012 and 2014) 
Table 2 Length of breastfeeding, Amenorrhoea and Sexual abstinence and time of first contraceptive use

\begin{tabular}{|c|c|c|c|c|c|c|c|c|}
\hline \multirow[t]{3}{*}{ Months after delivery } & \multicolumn{2}{|c|}{$\begin{array}{l}\text { Breastfeeding } \\
\text { (Yes) }\end{array}$} & \multicolumn{2}{|c|}{$\begin{array}{l}\text { Amenorrhoea } \\
\text { (Yes) }\end{array}$} & \multicolumn{2}{|c|}{$\begin{array}{l}\text { Sexual abstinence } \\
\text { (Yes) }\end{array}$} & \multicolumn{2}{|c|}{$\begin{array}{l}\text { First PPFP use } \\
\text { (Yes) }\end{array}$} \\
\hline & \multicolumn{2}{|l|}{$N=860$} & \multicolumn{2}{|l|}{$N=962$} & \multicolumn{2}{|l|}{$N=761$} & \multicolumn{2}{|l|}{$N=422$} \\
\hline & $\mathrm{n}(\%)$ & cum. $\%$ & $n(\%)$ & cum. $\%$ & $n(\%)$ & cum. $\%$ & $n(\%)$ & cum.\% \\
\hline 1 & $8(0.9)$ & 0.9 & $40(4.2)$ & 4.2 & $111(14.6)$ & 14.6 & $78(18.5)$ & 18.5 \\
\hline 2 & $14(1.6)$ & 2.5 & $12(1.3)$ & 5.5 & $128(16.8)$ & 31.4 & $102(24.2)$ & 42.7 \\
\hline 3 & $7(0.8)$ & 3.3 & $87(9.0)$ & 14.5 & $111(14.6)$ & 46.0 & $96(22.7)$ & 65.4 \\
\hline 4 & $13(1.5)$ & 4.8 & $50(5.2)$ & 19.7 & $154(20.2)$ & 66.2 & $38(9.0)$ & 74.4 \\
\hline 5 & $105(12.2)$ & 17.0 & 134(13.9) & 33.6 & $40(5.3)$ & 71.5 & $30(7.1)$ & 81.5 \\
\hline 6 & 616(71.6) & 88.6 & $37(3.9)$ & 37.5 & $74(9.7)$ & 81.2 & $28(6.6)$ & 88.1 \\
\hline $7-12$ & $97(11.3)$ & 100 & $602(62.5)$ & 100 & $143(18.8)$ & 100 & $50(11.9)$ & 100 \\
\hline
\end{tabular}

Source: field data 2014

Figure 2 shows the survival curves for first sexual resumption, first menstrual resumption and first contraceptive use by ordinal postpartum month. The survival curves show that the time at which $50 \%$ of the women had resumed their menses was about 6.3 months postpartum. Also, the time that $50 \%$ of them had resumed sex was 3.3 months postpartum, which is 3 months before resumption of first menses. This implies that women who were not using any postpartum contraceptive methods for any reason could be at risk of unintended pregnancy following resumption of sexual relations, especially when the intensity of breastfeeding could not be guaranteed (Reasons for non-use have been provided in Fig. 3). The time to first use of a modern contraceptive method during postpartum period indicates that about $50 \%$ of the women had used modern contraceptive methods by 2.7 months

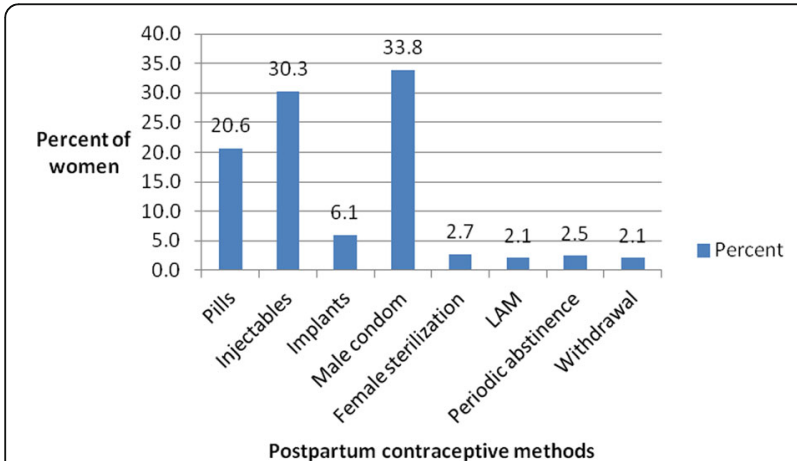

Fig. 1 Bar graph showing widely used postpartum contraceptive methods among women in the Mfantseman municipal of the central region of Ghana. Source:Field data 2014. Various postpartum contraceptive methods were used by the women These included oral contraceptive pills (pills), injectables, implants, male condoms, female sterilization, lactational amenorrhoea method (LAM), periodic abstinence and withdrawal method. Of all these methods, the ones that were used by most women were the male condom (33.8\%), injectables (30.3\%) and the oral contraceptive pills. The least used methods were the withdrawal (2.1\%) and lactational amenorrhoea (2.1\%) methods postpartum, and occured 0.6 and 3.6 months prior to resumption of sexual relations and menses respectively.

\section{Predictors of postpartum contraceptive use}

Tables 3 and 4 summarize the association between postpartum contraceptive use among women and their socio-demographic and reproductive characteristics respectively. Women's age $(p<0.001)$, educational level $(p<0.001)$, occupation $(p<0.001)$, area of residence $(p<0.001)$ and marital status $(p<0.001)$ were found to be associated with postpartum contraceptive use. However, ethnicity $(p=0.061)$ and religion $(p=0.287)$ of women were not associated with postpartum contraceptive use. There was an association between postpartum contraceptive use and resumption of sexual relationship $(p<0.001)$, amenorrhoea $(p<0.001)$, and breastfeeding $(p<0.001)$.

Table 5 presents the univariate and multivariate logistic regression analyses depicting the unadjusted (OR) and adjusted odds ratios (aOR) of factors that influence contraceptive use. All the variables that were associated with postpartum contraceptive use among women (Tables 3 and 4) were used to construct the univariate and the multivariate models.

In the univariate logistic regression, women within the age group 35-39 years were 2.62 times more likely to use postpartum contraceptive as compared to those within the age group 15-19 years $(\mathrm{OR}=2.62,95 \% \mathrm{CI}$ : $1.20-5.72, p=$ $0.015)$. Women with ages 40 years or above also had higher odds of using postpartum contraceptive as compared to adolescents (15-19 years). Women with Middle, Junior secondary school or Junior high school $(\mathrm{OR}=1.69,95 \% \mathrm{CI}$ : 1.06-2.69, $p=0.028$ ) also had increased likelihood of using postpartum contraceptive as compared with women without formal education. Civil or public servants were $48 \%$ less likely to use postpartum contraceptive as compared to fish mongers $(\mathrm{OR}=0.52,95 \% \mathrm{CI}: 0.28-0.95, p=0.034)$. Women living in Anomabo $(\mathrm{OR}=2.69,95 \% \mathrm{CI}: 1.80-3.99, p<$ $0.001)$ and Mankessim (OR $=0.71,95 \%$ CI: 0.51-0.99, $p=$ 


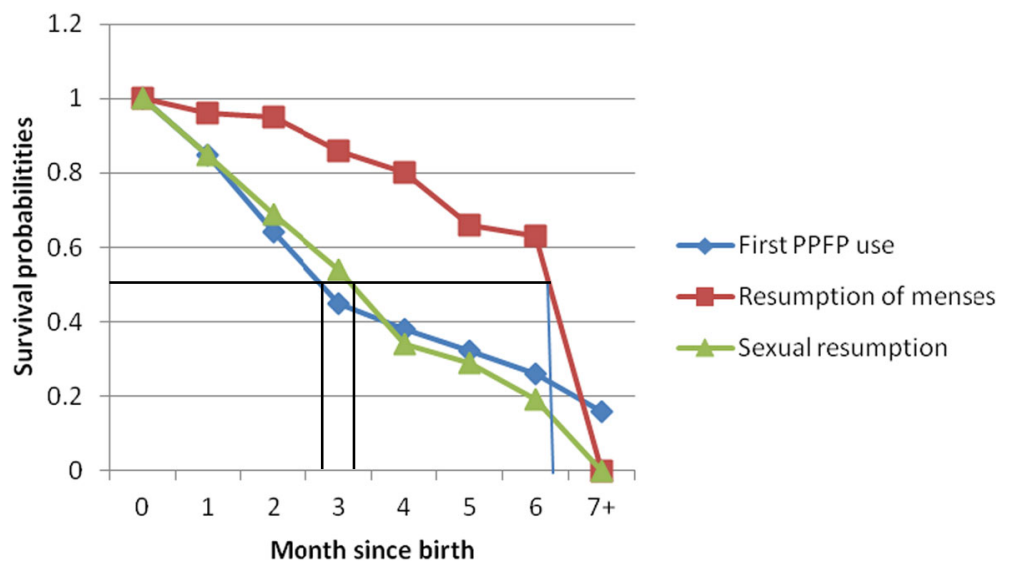

Fig. 2 Survival curves depicting first menstrual resumption, sexual resumption and use of postpartum family planning among postpartum women in the Mfantseman municipal. Source: Field data 2014. The X-axis represents the months since delivery, whilst the Y-axis represents the survival probabilities. The red, blue and green line graphs represent the time of resumption of menses, time of postpartum family planning (PPFP) use and time of resumption of sexual following delivery respectively. The figure shows that postpartum family planning use by $50 \%$ of the women was at 2.7 months postpartum. This was 0.6 and 3.6 months prior to resumption of sexual relations and menses respectively

0.045) had higher and lower odds respectively of using postpartum contraceptive as compared to women living in Saltpond. Moreover, women who were married through traditional rites $(\mathrm{OR}=0.66,95 \% \mathrm{CI}: 0.47-0.92, p=0.013)$, engaged $(\mathrm{OR}=0.42,95 \% \mathrm{CI}: 0.29-0.61, p<0.001)$ and were single, separated, widowed or divorced $(\mathrm{OR}=0.47,95 \% \mathrm{CI}$ : $0.24-0.91, p=0.026$ ) were less likely to use postpartum contraceptive. Women with assisted vaginal delivery were $87 \%$ less likely to use postpartum contraceptive as compared to women who had spontaneous vaginal delivery (SVD) (OR $=0.13,95 \%$ CI: 0.07-0.25, $p<0.001)$. Compared to women who had complications, those who did not have

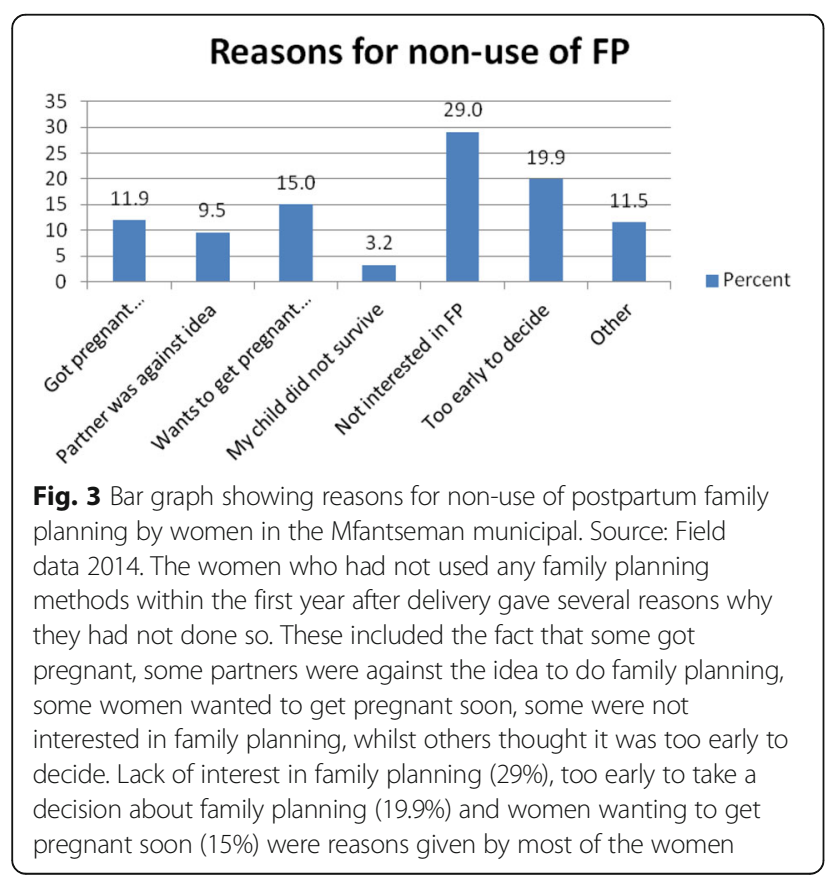

complications had decreased likelihood of using postpartum contraceptive ( $\mathrm{OR}=0.33,95 \% \mathrm{CI}: 0.33-0.65, p<$ $0.001)$. In addition, women who were not breastfeeding had two-fold of using postpartum contraceptive $(\mathrm{OR}=2.04$, 95\% CI: $1.50-2.78, p<0.001)$. Amenorrhoeic women were $52 \%$ less likely to use postpartum contraceptive $(\mathrm{OR}=0.48$, 95\% CI: $0.32-0.72, p<0.001)$. For a unit increase in the women's preferred number of children, their odds of using postpartum contraceptive increased more than two-fold $(\mathrm{OR}=2.16,95 \% \mathrm{CI}: 1.78-2.63, p<0.001)$. For a unit increase in parity, the likelihood of women using postpartum contraceptive increased by 1.9 (OR $=1.90,95 \%$ CI: $1.71-$ $2.10, p<0.001)$.

\section{Multivariate regression}

In the multivariate logistic regression, occupation (likelihood ratio $p=0.013$ ), area of residence (likelihood ratio $p$ $=0.004$ ), mode of delivery (likelihood ratio $p<0.001$ ), breastfeeding $(p=0.024)$, period since delivery $(p<0.001)$, preferred number of children $(p<0.001)$ and parity $(p<$ 0.001 ) were found to be predictors of postpartum contraceptive use. Women who were students $(\mathrm{aOR}=5.00,95 \%$ CI: 1.12-22.40, $p=0.035$ ) had higher odds of using postpartum contraceptives. Women living in Mankessim ( $\mathrm{aOR}=0.58,95 \%$ CI: 0.34-0.99, $p=0.049$ ) were less likely to use postpartum contraceptives as compared with those living in Saltpond. Compared with those who had SVD, women who had assisted vaginal delivery were $80 \%$ less likely $(\mathrm{aOR}=0.20,95 \% \mathrm{CI}: 0.06-0.70, p=0.012)$ to use postpartum contraceptive, whereas women who had caesarean section had 5.12 times $(\mathrm{aOR}=5.12$, 95\% CI: $2.24-$ 11.68, $p=0.049$ ) likelihood of using postpartum contraceptive. Women who did not breastfeed had more than double likelihood of using postpartum contraceptive (aOR 
Table 3 Association between postpartum contraceptive use and socio-demographic characteristics of respondents

\begin{tabular}{|c|c|c|c|c|}
\hline \multirow[t]{3}{*}{ Variable } & Yes & No & \multirow[t]{3}{*}{$x^{2}$} & \multirow[t]{3}{*}{$p$-value } \\
\hline & $\mathrm{N}=505$ & $N=498$ & & \\
\hline & n (\%) & n (\%) & & \\
\hline \multicolumn{5}{|l|}{ Age } \\
\hline $15-19$ & $14(42.4)$ & 19(57.6) & & \\
\hline $20-34$ & $343(46.3)$ & 398(53.7) & & \\
\hline $35-39$ & $87(65.9)$ & $45(34.1)$ & & \\
\hline $40+$ & $61(62.9)$ & $36(37.1)$ & 24.60 & $<0.001$ \\
\hline \multicolumn{5}{|l|}{ Educational level } \\
\hline None & $36(43.4)$ & $47(56.6)$ & & \\
\hline Primary & $102(47.7)$ & $112(52.3)$ & & \\
\hline $\begin{array}{l}\text { Middle/Junior secondary } \\
\text { School/Junior high school }\end{array}$ & $306(56.4)$ & $237(43.7)$ & & \\
\hline $\begin{array}{l}\text { Secondary/Senior secondary } \\
\text { school/Senior high School }\end{array}$ & $44(37.0)$ & $75(63.0)$ & & \\
\hline Tertiary & 17(38.6) & $27(61.4)$ & 21.00 & $<0.001$ \\
\hline \multicolumn{5}{|l|}{ Ethnicity } \\
\hline Fante & $452(50.8)$ & $438(49.2)$ & & \\
\hline Efutu & $3(16.7)$ & $15(83.3)$ & & \\
\hline Other Akan & $22(47.8)$ & $24(52.2)$ & & \\
\hline Ewe & 13(61.9) & $8(38.1)$ & & \\
\hline Hausa & $11(50.0)$ & $11(50)$ & & \\
\hline Other & $4(66.7)$ & $2(33.3)$ & 10.11 & 0.061 \\
\hline \multicolumn{5}{|l|}{ Religion } \\
\hline Christian & $459(50.7)$ & $447(49.3)$ & & \\
\hline Muslim & $39(51.3)$ & $37(48.7)$ & & \\
\hline Other & $7(33.3)$ & 14(66.7) & 2.50 & 0.287 \\
\hline \multicolumn{5}{|l|}{ Occupation } \\
\hline Fishmonger & $36(52.2)$ & $33(47.8)$ & & \\
\hline Farmer & $7(21.2)$ & $26(78.8)$ & & \\
\hline Petty Trader & $307(59.6)$ & $208(40.4)$ & & \\
\hline Civil/Public Servant & $40(36.0)$ & $71(64.0)$ & & \\
\hline Student & $18(56.3)$ & $14(43.8)$ & & \\
\hline Other & 97(39.9) & $146(60.1)$ & 49.09 & $<0.001$ \\
\hline \multicolumn{5}{|l|}{ Area of residence } \\
\hline Saltpond & 157(49.7) & 159(50.3) & & \\
\hline Biriwa & $60(44.4)$ & $75(55.6)$ & & \\
\hline Anomabo & 130(72.6) & $49(27.4)$ & & \\
\hline Mankessim & 107(41.3) & 152(58.7) & & \\
\hline Other & $51(44.7)$ & $63(55.3)$ & 47.37 & $<0.001$ \\
\hline \multicolumn{5}{|l|}{ Marital Status } \\
\hline $\begin{array}{l}\text { Married through church/ } \\
\text { mosque/court wedding }\end{array}$ & $129(60.6)$ & 84(39.4) & & \\
\hline Married only by traditional rite & 218(50.2) & 216(49.8) & & \\
\hline Engaged, yet to be married & $94(39.2)$ & $146(60.8)$ & & \\
\hline
\end{tabular}

Table 3 Association between postpartum contraceptive use and socio-demographic characteristics of respondents (Continued)

\begin{tabular}{lllll}
\hline Variable & Yes & No & $x^{2}$ & $p$-value \\
& $\mathrm{N}=505$ & $\mathrm{~N}=498$ & & \\
& $\mathrm{n}(\%)$ & $\mathrm{n}(\%)$ & & \\
\hline Co-habitation (living together) & $46(63.0)$ & $27(37.0)$ & & \\
$\begin{array}{l}\text { Divorced/Separated/ } \\
\text { Widow/Single }\end{array}$ & $18(41.9)$ & $25(58.1)$ & 26.82 & $<0.001$ \\
\hline
\end{tabular}

$=2.16,95 \%$ CI: $1.11-4.21, p=0.024)$ compared to those who breastfed. For a unit increase in the period since delivery, the women were 0.89 times less likely to use postpartum contraceptive (aOR $=0.89,95 \%$ CI: $0.84-0.95, p<$ 0.001 ). For a unit increase in the preferred number of children, the odds of using postpartum contraceptive increased among women $(\mathrm{aOR}=3.95,95 \% \mathrm{CI}: 2.77-5.62, p$ $<0.001$ ). For a unit increase in parity, the likelihood of women using postpartum contraceptive increased by 2.3 $(\mathrm{aOR}=2.26,95 \%$ CI: $1.83-2.78, p<0.001)$.

\section{Discussion}

The objectives of the study were to: assess how protected postpartum women in the Mfantseman municipal were against pregnancy, based on their patterns of amenorrhoea and sexual abstinence; determine the timing of postpartum contraception in relation to amenorrhoea and sexual abstinence; and determine the predictors of postpartum contraceptive use. The intensity and duration of breastfeeding, length of amenorrhoea and sexual abstinence, individually or in combination affect women's risk of getting pregnant within the extended postpartum period and before the two-year recommended spacing period after the last birth [1], especially in the absence of contraceptive use. Traditionally, women in sub-Saharan Africa relied mainly on breastfeeding, amenorrhoea and sexual abstinence to space their births. Periods of breastfeeding for as long as two years and its attendant long duration of amenorrhoea in some settings and long periods of sexual abstinence in middle and West Africa, were the norm [11].

Increasing modernization, urbanization and social change have gradually reduced the effectiveness of these traditional birth spacing mechanisms and therefore women have increasingly been at risk of unintended pregnancies in the postpartum period [12]. The mean duration of breastfeeding among the study participants was $6.6 \pm$ 2.8. This is greater than the mean duration of exclusive breastfeeding in Ghana of 3.9 months and less than the mean duration of any breastfeeding of 21.2 months in Ghana and 20.4 months in the central region respectively [13]. The mean duration of any breastfeeding in the municipality was about $14 \%$ lower than that of the region and was among the lowest in the region. This may be due to 
Table 4 Association between postpartum contraceptive use and reproductive characteristics

\begin{tabular}{|c|c|c|c|c|}
\hline \multirow[t]{3}{*}{ Variable } & Yes & No & \multirow[t]{3}{*}{$x^{2}$} & \multirow[t]{3}{*}{$p$-value } \\
\hline & $N=505$ & $N=498$ & & \\
\hline & n (\%) & n (\%) & & \\
\hline \multicolumn{5}{|l|}{ Outcome of last pregnancy } \\
\hline Live term baby & $498(50.6)$ & $487(49.4)$ & & \\
\hline Stillbirth/Miscarriage & $7(38.9)$ & $11(61.1)$ & 0.96 & 0.326 \\
\hline \multicolumn{5}{|l|}{ Place of delivery } \\
\hline Home & 18(54.6) & $15(45.5)$ & & \\
\hline Public hospital/Private hospital/Maternity home & $487(50.2)$ & $483(49.8)$ & 0.24 & 0.624 \\
\hline \multicolumn{5}{|l|}{ Mode of delivery } \\
\hline SVD & $455(53.1)$ & $402(46.9)$ & & \\
\hline Assisted vaginal delivery & 11(13.1) & 73(86.9) & & \\
\hline Caesarean section & $39(62.9)$ & 23(37.1) & 53.12 & $<0.001$ \\
\hline \multicolumn{5}{|l|}{ Delivery complications } \\
\hline Yes & 116(65.9) & $60(34.1)$ & & \\
\hline No & $388(47.00)$ & $437(53.0)$ & 20.68 & $<0.001$ \\
\hline \multicolumn{5}{|l|}{ Resumed sexual relationship since last birth } \\
\hline Yes & $471(53.6)$ & 408(46.4) & & \\
\hline No & $34(27.4)$ & $90(72.6)$ & 29.76 & $<0.001$ \\
\hline \multicolumn{5}{|l|}{ Ever breastfed after delivery } \\
\hline Yes & $363(46.5)$ & $418(53.5)$ & & \\
\hline No & $142(64.0)$ & $80(36.0)$ & 21.14 & $<0.001$ \\
\hline \multicolumn{5}{|l|}{ Return of menses since last birth (amenorrhoea)? } \\
\hline Yes & $466(52.4)$ & $424(47.6)$ & & \\
\hline \multirow[t]{2}{*}{ No } & $39(34.5)$ & $74(65.5)$ & 12.77 & $<0.001$ \\
\hline & $\mathrm{n}$ (Arithmetic mean) & n (Arithmetic mean) & & \\
\hline Date of delivery in months ${ }^{a}$ & 493(15.7) & $490(17.5)$ & & $<0.001$ \\
\hline How many Months after birth did you not have your period was not had? ${ }^{a}$ & $482(8.0)$ & $480(7.6)$ & & 0.080 \\
\hline Number of children ever born/Parity of the last birth ${ }^{a}$ & $505(3.4)$ & $498(2.0)$ & & $<0.001$ \\
\hline Preferred number of children ${ }^{a}$ & $388(3.7)$ & $355(3.2)$ & & $<0.001$ \\
\hline
\end{tabular}

anpaired t-test was used to determine association

Source: Field data (2014

the increase in the use of bottle feeding (which some women consider as modern) which also increased in the country between 2008 and 2014 [13].

Postpartum protection from conception depends upon the intensity and duration of breastfeeding. In the absence of reasonably intensive breastfeeding, women are likely to ovulate before the end of the second postpartum month and hence become susceptible to pregnancy [14]. A woman is considered insusceptible if she is not exposed to the risk of pregnancy, either because she is amenorrhoeic as a result of reasonably intensive breastfeeding exclusively for the first six months or because she is abstaining from sexual intercourse following birth [13]. The median duration of amenorrhoea and sexual abstinence among the respondents were 7.8 and 4.4 months respectively. These were shorter than the median durations of amenorrhoea and sexual abstinence for central region (9.9 and 6.6 months) and Ghana (8.4 and 5.9 months) respectively [13]. The relatively shorter durations of amenorrhoea may be due to the shorter duration and lower intensity of breastfeeding among the women in the municipality. The relatively shorter durations of sexual abstinence and amenorrhoea and the lower intensity of breastfeeding may expose the women in the municipality to the risk of unintended pregnancy, especially in the absence of contraceptive use. This may explain the high rates of unintended pregnancy among pregnant women in the municipality [15].

Among the women who used contraceptives, time of initiation was earlier than initiation of sexual relations and first menses following their last birth. Mean time of initiation of 
Table 5 Predictors of contraceptive use among postpartum women attending antenatal clinic at Mfantseman Municipal

\begin{tabular}{|c|c|c|c|c|}
\hline \multirow[b]{2}{*}{ Variable } & \multicolumn{2}{|l|}{ Univariate Model } & \multicolumn{2}{|c|}{ Multivariate Model } \\
\hline & OR $(95 \% \mathrm{Cl})$ & $p$-value & $\mathrm{aOR}(95 \% \mathrm{Cl})$ & $p$-value \\
\hline \multicolumn{5}{|l|}{ Age } \\
\hline $15-19$ & 1 & & 1 & \\
\hline $20-34$ & $1.16(0.58-2.37)$ & 0.663 & $0.47(0.14-1.57)$ & 0.221 \\
\hline $35-39$ & $2.62(1.20-5.72)$ & 0.015 & $0.48(0.12-1.89)$ & 0.292 \\
\hline $40+$ & $2.30(1.03-5.13)$ & 0.042 & $0.47(0.11-2.02)$ & 0.308 \\
\hline \multicolumn{5}{|l|}{ Educational level } \\
\hline None & 1 & & 1 & \\
\hline Primary & $1.19(0.71-1.98)$ & 0.506 & $1.86(0.73-4.75)$ & 0.192 \\
\hline Middle/Junior secondary school/Junior high school & $1.69(1.06-2.69)$ & 0.028 & $2.00(0.85-4.71)$ & 0.115 \\
\hline Secondary/Senior secondary school/Senior high school & $0.77(0.43-1.35)$ & 0.361 & $2.22(0.80-6.16)$ & 0.126 \\
\hline Tertiary & $0.82(0.39-1.73)$ & 0.607 & $1.84(0.39-8.62)$ & 0.441 \\
\hline \multicolumn{5}{|l|}{ Occupation } \\
\hline Fishmonger & 1 & & 1 & \\
\hline Farmer & $0.23(0.09-0.64)$ & 0.004 & $0.20(0.03-1.28)$ & 0.090 \\
\hline Petty Trader & $1.35(0.82-2.24)$ & 0.240 & $2.23(0.96-5.16)$ & 0.061 \\
\hline Civil/Public Servant & $0.52(0.28-0.95)$ & 0.034 & $1.94(0.57-6.62)$ & 0.288 \\
\hline Student & $1.18(0.51-2.74)$ & 0.703 & $5.00(1.12-22.40)$ & 0.035 \\
\hline Other & $0.61(0.36-1.04)$ & 0.071 & $1.46(0.60-3.53)$ & 0.405 \\
\hline \multicolumn{5}{|l|}{ Area of residence } \\
\hline Saltpond & 1 & & 1 & \\
\hline Biriwa & $0.81(0.54-1.21)$ & 0.308 & $2.03(0.90-4.57)$ & 0.089 \\
\hline Anomabo & $2.69(1.80-3.99)$ & $<0.001$ & $1.86(0.98-3.52)$ & 0.059 \\
\hline Mankessim & $0.71(0.51-0.99)$ & 0.045 & $0.58(0.34-0.99)$ & 0.049 \\
\hline Other & $0.81(0.53-1.26)$ & 0.365 & $0.84(0.44-1.60)$ & 0.601 \\
\hline \multicolumn{5}{|l|}{ Marital Status } \\
\hline Married through Church/Mosque/Court wedding & 1 & & 1 & \\
\hline Married only by traditional rites & $0.66(0.47-0.92)$ & 0.013 & $1.16(0.68-2.01)$ & 0.581 \\
\hline Engaged, yet to marry & $0.42(0.29-0.61)$ & $<0.001$ & $1.23(0.64-2.41)$ & 0.532 \\
\hline Co-habitation & $1.11(0.64-1.92)$ & 0.711 & $1.47(0.64-3.39)$ & 0.370 \\
\hline Divorced/Separated/Widowed/Single & $0.47(0.24-0.91)$ & 0.026 & $0.27(0.07-1.10)$ & 0.068 \\
\hline \multicolumn{5}{|l|}{ Mode of delivery } \\
\hline Spontaneous Vaginal Delivery & 1 & & 1 & \\
\hline Assisted vaginal delivery & $0.13(0.07-0.25)$ & $<0.001$ & $0.20(0.06-0.70)$ & 0.012 \\
\hline Caesarean section & $1.50(0.88-2.55)$ & 0.137 & $5.12(2.24-11.68)$ & $<0.001$ \\
\hline \multicolumn{5}{|l|}{ Any delivery complications } \\
\hline Yes & 1 & & 1 & \\
\hline No & $0.46(0.33-0.65)$ & $<0.001$ & $2.14(0.92-4.94)$ & 0.076 \\
\hline \multicolumn{5}{|l|}{ Resumed sexual relationship since birth } \\
\hline Yes & 1 & & 1 & \\
\hline No & $0.33(0.22-0.50)$ & $<0.001$ & $0.89(0.41-1.98)$ & 0.784 \\
\hline \multicolumn{5}{|l|}{ Ever breastfed after delivery } \\
\hline Yes & 1 & & 1 & \\
\hline No & $2.04(1.50-2.780)$ & $<0.001$ & $2.16(1.11-4.21)$ & 0.024 \\
\hline
\end{tabular}


Table 5 Predictors of contraceptive use among postpartum women attending antenatal clinic at Mfantseman Municipal (Continued)

\begin{tabular}{|c|c|c|c|c|}
\hline \multirow[b]{2}{*}{ Variable } & \multicolumn{2}{|c|}{ Univariate Model } & \multicolumn{2}{|c|}{ Multivariate Model } \\
\hline & OR $(95 \% \mathrm{Cl})$ & $p$-value & $\mathrm{aOR}(95 \% \mathrm{Cl})$ & $p$-value \\
\hline \multicolumn{5}{|l|}{ Return of menses since your last birth } \\
\hline Yes & 1 & & 1 & \\
\hline No & $0.48(0.32-0.72)$ & $<0.001$ & $1.65(0.81-3.38)$ & 0.168 \\
\hline Date of delivery in months & $0.90(0.88-0.93)$ & $<0.001$ & $0.89(0.84-0.95)$ & $<0.001$ \\
\hline Preferred number of children & $2.16(1.78-2.63)$ & $<0.001$ & $3.95(2.77-5.62)$ & $<0.001$ \\
\hline Number of children ever born/Parity of the last child & $1.90(1.71-2.10)$ & $<0.001$ & $2.26(1.83-2.78)$ & $<0.001$ \\
\hline
\end{tabular}

Source: Field data (2014)

contraceptive was 3.5 months following birth. Among this group of women, $50 \%$ had initiated contraceptive use 0.6 and 3.6 months earlier than initiation of sexual relations and first menses respectively at 2.7 months after birth. This was in contrast with what was observed in a study in urban slums in Nairobi where initiation of postpartum contraceptive use by $50 \%$ of the women had occurred 7 months after birth, 4 months after initiation of sexual relations and a month after first menses [12]. The relationship observed between postpartum contraceptives use, the initiation of sexual relations and first menses in the Mfantseman municipal is not very common in sub-Saharan Africa [16-18]. The finding that women who adopted contraceptives did so early and prior to resumption of sexual relations and first menses is generally encouraging; however, it must be borne in mind that it does not guarantee the prevention of unintended pregnancies and adequate spacing of births, unless the methods adopted were not discontinued or unless permanent methods were adopted. In this study, the women after initiation of contraceptives did not report discontinuation within the first year postpartum. The most widely used methods adopted among the women in the Mfantseman municipal were male condoms, followed by injectables and pills. In Ghana, the most widely used methods among married women were injectables, implants and pills, whilst male condoms, pills and injectables were the most widely used among unmarried women [14]. The methods used among the women were different because there were several methods available and the women had the freedom to choose which methods were suitable for them. Among postpartum women in a study among urban slum dwellers in Nairobi, the most widely used methods were injectables and pills [12].

It is not easy to predict how early the return of ovulation and menses for a particular woman who did not breastfeed would be. However, evidence exist that women who do not breastfeed after birth usually have early return of ovulation and menses and are thus at greater risk of unintended pregnancies. Education about this fact is provided by midwives during antenatal care in Ghana and other settings. In this study women who did not breastfeed after birth were found to be more likely to use postpartum contraceptives compared to those who breastfed. This is consistent with a study in Egypt where women who exclusively breastfed were less likely to use modern methods of contraception postpartum [19].

In this study, women who underwent caesarean section were five times likely to use postpartum contraceptives compared to those who delivered via spontaneous vaginal delivery. In contrast, those who had assisted vaginal delivery were less likely to use postpartum contraceptives. The reasons for this difference are not very clear in this study setting; however it is known that women who underwent caesarean section were often inclined to use some form of postpartum contraception and preferred methods like bilateral tubal ligation, intrauterine device and injectables [20, 21 in order to avoid repeat caesarean section from another pregnancy too soon. Consistent with a study in Iran [22], place of residence influences contraceptive use among postpartum. Women living in Mankessim were less likely to use postpartum contraceptives compared to those resident in Saltpond. This was unexpected in the sense that women from Mankessim had the highest awareness (83\%) about postpartum contraceptives [15] yet were the least likely to use them. Myths, fear of side effects and opposition by significant others may likely influence this observation. Further inquiry may be required to ascertain these facts. The finding in this study that students were more likely than fishmongers to adopt postpartum contraceptives is encouraging in the sense that girls may need to go back to school to complete and advance their educational status in line with the Ghana Education Service's policy and also to avoid any future unintended pregnancies. High Parity has been found in several studies to be associated with contraceptive use [23-25]. The finding in this study is similar. Women of high parity may have satisfied the number and sex of their children and may wish to limit their births.

\section{Strengths and limitations of study}

The prospective design was appropriate for the study considering the fact that accurate timing of postpartum reproductive health events was important to establish the relationship between them and contraceptive use. Although some strategies were put in place to minimize 
non-response and attrition (see methodology), the rate nevertheless was still very high (wave I response rate of $97 \%$ versus wave II response rate of $51 \%$ ) and lead to sampling bias, reduced generalizability of study results and increased variance of study estimates. The threat of selection bias existed, but was highly mitigated by ensuring that the data collectors explained the study objectives and their implications very well to the respondents. The study findings may not be generalizable to the national and regional populations but to coastal and predominantly rural populations within the central region and country. The absence of data on duration of family planning use, seriously limits any conclusions about pregnancy risk in the first postpartum year. Some of the data collectors abandoned the study because of inadequate remuneration. New data collectors had to be trained to continue data collection. This brought about some delays in data analysis and reporting.

\section{Conclusion}

The objectives of this study were to assess how protected postpartum women in the Mfantseman municipal were against pregnancy, based on their patterns of amenorrhoea and sexual abstinence; determine the timing of postpartum contraception in relation to amenorrhoea and sexual abstinence; and determine the predictors of postpartum contraceptive use. Postpartum women in the Mfantseman municipal who did not use contraceptives or delayed in the use of contraceptives after birth were least likely to be protected against pregnancy in the post partum period because of early initiation of postpartum sexual relations, poor intensity and relatively shorter duration of breastfeeding. Women who adopted postpartum family planning were likely to be better protected because they were likely to adopt it within the first three months after birth and before the onset of sexual relations and first menses. The predictors of postpartum contraceptive use were breastfeeding pattern, occupation, parity, preferred number of children, place of residence and mode of delivery.

\section{Abbreviations \\ FP: Family Planning; GSS: Ghana Statistical Service; PPFP: Postpartum family planning; SVD: Spontaneous vaginal dellivery; WHO: World Health Orgaization}

\section{Funding}

Funding for this study was self.

\section{Availability of data and materials}

The data that supports the study has individual identifiers and researcher is reserved to provide it.

\section{Authors' contributions}

SE: Conceptualized the study was involved in data collection, entry and analysis and developed the paper; CE was involved in data collection, analysis and reviewed the paper; ASB was involved in data collection, entry and analysis and reviewed the final paper. All authors read and approved the final manuscript.

\section{Ethics approval and consent to participate}

Ethical and administrative approvals were obtained from the Ethics Review Committee of the Ghana Health Service and the Municipal Health Directorate (GHS-ERC: 14/09/11). Written informed consent was obtained from each participant and witnessed.

Before each interview, the aims, objectives and benefits of the study were explained to respondents; they were then allowed to ask any questions for clarifications. Once they consented, they were made to sign with a witness of their choice. Interviews were conducted in places that guaranteed maximum privacy. For individuals who could have emotional problems from interviews, a Clinical Psychologist from University of Cape Coast was recruited on stand-by to handle cases that were beyond the control of the Principal Investigator.

\section{Consent for publication}

Consent was obtained from all the participants to publish information obtained from them but without the personal identifiers. These were also witnessed accordingly.

\section{Competing interests}

The authors declare that they have no competing interests.

\section{Publisher's Note}

Springer Nature remains neutral with regard to jurisdictional claims in published maps and institutional affiliations.

\section{Author details}

'Department of Community Medicine, School of Medical Sciences, University of Cape Coast, Cape Coast, Ghana. ${ }^{2}$ FWACN School of Nursing and Midwifery, University of Ghana, Accra, Ghana.

Received: 20 October 2017 Accepted: 15 May 2018

Published online: 20 August 2018

References

1. World Health Organization. Report of a WHO Technical Consultation on Birth Spacing, Geneva Switzerland, 13-15 June 2005. Geneva: WHO; 2006.

2. Cleland J, Bernstein S, Ezeh A, Faundes A, Glasier A, Innis J. Family planning: the unfinished agenda. Lancet. 2006;368(9549):1810-27.

3. Rutstein SO. Further evidence of the effects of preceding birth intervals on neonatal infant and under-five-years mortality and nutritional status in developing countries: Evidence from the Demographic and Health Surveys. 2008. https://www.dhsprogram.com/pubs/WP41/WP41.pdf. Accessed 5 Oct 2017.

4. Stover J, Ross J. How increased contraceptive use has reduced maternal mortality. Matern Child Health J. 2010;14(5):687-95.

5. Borda M, Winfrey W. Postpartum Fertility and Contraception: an analysis of findings from 17 countries. Futures/constella for ACCESS-FP 2010, Jhpiego: Baltimore, Maryland.

6. Gebreselassie T, Rutstein SO, Mishra V. Contraceptive Use, Breastfeeding, Amenorrhea and Abstinence during the postpartum period: an analysis of four countries. In: DHS Analytical Studies, vol. 14. Calverton, Maryland: Macro International Inc; 2008. https://www.dhsprogram.com/pubs/pdf/AS14/AS14. pdf.

7. Bongaarts JA. Framework for Analyzing the Proximate Determinants of Fertility. Popul Dev Rev. 1978:105-32.

8. Ghana Health Service, Municipal Health Directorate, Mfantseman Annual Report 2010;25.

9. Creative Research Systems 2012. Creative Research Systems Sample Size Calculator. https://www.surveysystems.com/sscalc.htm. Retrieved August 21, 2015

10. Ghana Health Service, Central Region. (2011). Family Health Report 2010.

11. Rossier C, Hellen J. Traditional birth spacing practices and Uptake of family planning during the postpartum period in Ouagadougou: qualitative results. Int Perspect Sex Reprod Health 2014; 40(2): 87-94 https://www.guttmacher. org/journals/ipsrh/2014/07/traditional-birthspacing-practices-and-uptakefamily-planning-during Jul 8, 2014.

12. Robert P, Ndugwa RP, Cleland J, Nyovani J, Madise NJ, Fotso JC, Zulu EM. Menstrual pattern, sexual behaviors, and contraceptive use among postpartum women in Nairobi urban slums. J Urban Health. 2011;88(2):34155. https://doi.org/10.1007/s11524-010-9452-6. 
13. Ghana Statistical Service (GSS), Ghana Health Service (GHS), and ICF International. Ghana demographic and health survey 2014. Rockville, Maryland: GSS, GHS, and ICF International; 2015.

14. Speroff $L$, Mishell DR. The postpartum visit: It's time for a change in order to optimally initiate contraception. Contraception. 2008;78(2):90-8. https://doi. org/10.1016/j.contraception.2008.04.005.

15. Eliason S, Baiden F, Quansah-Asare G, Graham-Hayfron Y, Bonsu D, Phillips J, Awusabo-Asare K. Factors influencing the intention of women in rural Ghana to adopt postpartum family planning. Reprod Health 2013; 10:34 https://doi.org/10.1186/1742-4755-10-34

16. Clements S, Madise N. Who is being served least by family planning providers? A study of modern contraceptive use in Ghana, Tanzania and Zimbabwe. Afr J Reprod Health. 2004;8(2):124-36. https://doi.org/10.2307/ 358318

17. Ronsmans C. Birth spacing and child survival in rural Senegal. Int J Epidemiol. 1996;25(5):989-97. https://doi.org/10.1093/ije/25.5.989.

18. Magadi MA, Zulu EM, Brockerhoff M. The inequality of maternal health care in urban sub-Saharan Africa in the 1990s. Popul Stud (Camb). 2003;57(3): 347-66. https://doi.org/10.1080/0032472032000137853.

19. Afifi M. Lactational Amenorrhoea and modern contraceptives use among nursing women in Egypt 2003. Oman Med J. 2008;23(2):72-7.

20. Upmanyu P, Kanhere A. Acceptance of methods of family planning in patients undergoing repeat caesarean section. International Journal of Reproduction, Contraception, Obstetrics and Gynecology. 2016;5(4):976-9.

21. Goldstuck ND, Steyn PS. Insertion of intrauterine devices after cesarean section: a systematic review update. Int J Womens Health. 2017;(9):205-12.

22. Rahmanpour H, Mousavinasab SN, Hosseini SN, Shoghli A. Preferred postpartum contraception methods and their practice among married women in Zanjan, Iran. J Pak Med Assoc. 2010;60(9):714-8.

23. Sharma V, Mohan U, Das V, Awasthi S. Socio demographic determinants and knowledge, attitude, practice: survey of family planning. J Family Med Prim Care. 2012;1(1):43.

24. Lakew YAA, Tamene H, Benedict S, Deribe K. Geographical variation and factors influencing modern contraceptive use among married women in Ethiopia: evidence from a national population based survey. Reprod Health. 2013;10:52.

25. Jabeen M, Gul F, Wazir F, Javed N. Knowledge, attitude and practices of contraception in women of reproductive age. Gomal Journal of Medical Sciences, 2012:9(2):113-6.

\section{Ready to submit your research? Choose BMC and benefit from}

- fast, convenient online submission

- thorough peer review by experienced researchers in your field

- rapid publication on acceptance

- support for research data, including large and complex data types

- gold Open Access which fosters wider collaboration and increased citations - maximum visibility for your research: over $100 \mathrm{M}$ website views per year

At BMC, research is always in progress.

Learn more biomedcentral.com/submissions 